\title{
What students who perform in "secondary roles" can learn from scenario training in vocational education
}

\author{
David Sjöberg ${ }^{* 1}$, Staffan Karp ${ }^{2}$, Oscar Rantatalo ${ }^{2}$ \\ ${ }^{1}$ Unit for Police Education, Umeå University, 90187 Umeå, Sweden \\ ${ }^{2}$ Department of Education, Umeå University, 90187 Umeå, Sweden
}

Received: 27.05.2018, Accepted: 12.12.2018, Published: 30.04.2019

\begin{abstract}
Context: Learning through scenario training and live simulation in vocational education is generally regarded as an effective tool for developing professional knowledge. However, previous research has largely overlooked the learning of students in secondary roles in scenario training. The objective of this study is to explore learning for students who act in secondary roles during scenario training in vocational educational settings.

Method: The studied case entails scenario training for police students in a Swedish police education programme. A case study design, which included both participant observation and a questionnaire, was used. The analytic lens applied was inspired by practice theory and focused on how structural and situational arrangements of the training activity affect learning.

Results: Our findings show that students who act in secondary roles learn from their scenario training experiences, but this learning often is overlooked in the design of training activities. Due to the structural arrangements of training activities, learning emerged as students in secondary roles were tasked to support the primary participants in relation to their learning objectives. In addition, it emerged in how students in secondary roles used previous scenario training experiences in relation to the current scenario and its learning objectives. Examples of learning from situational arrangements emerged as students in secondary roles formulated and provided feedback to primary participants and through informal discussions and reflection processes. Learning also emerged as students in secondary roles embo-
\end{abstract}

*Corresponding author: david.sjoberg@umu.se

ISSN: $2197-8646$

http://www.ijrvet.net

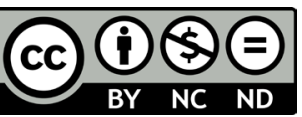


died the "other" during scenario training, something that provided the students with new perspectives on police encounters.

Conclusions: We theorize and extract three dimensions for how learning emerges in this case for secondary participants. It emerges through embodying the "other", in students' sensory experiences, and through reconstruction of knowledge through repetition. However, our findings also show that learning for students in secondary roles can be improved through mindful set-up and design. Based on the findings, our article provides a discussion and suggestions on how scenario training can be planned and set-up to develop professional knowledge for students in secondary roles.

Keywords: Scenario training, simulation, vocational education and training, learning, police education, practice, VET

\section{Introduction}

Scenario training is integral to educational activities in many professional and vocational educational settings where the development of reliable operational work performance is of importance (Rooney, Hopwood, Boud \& Kelly, 2015). Examples of such settings include medical education (Rystedt \& Sjöblom, 2012), fire services training (Childs, 2005) and police education (Sjöberg, Karp, \& Söderström, 2015). In educational contexts such as these, scenario training is generally viewed as a fruitful approach for giving students opportunities to experience and make sense of relevant professional situations (Crookall, 2010). Studies have shown that, through scenario training, students can probe different behavioural and tactical approaches, take on different roles, and gain understandings of their own, as well as others', behaviours in work situations (Nestel \& Tierney, 2007). Furthermore, scenario training can provide a protected environment that allows students to repeatedly train in situations that can be both common and rare in professional practice, and sometimes even dangerous (Rooney et al. 2015; Kneebone, 2005). Research on scenario training has indicated that this type of activity has merits in that it helps students to gain experience and to develop professional knowing for their future occupational practice (Andersson 2016; Sjöberg, 2014; Bland, Topping \& Wood, 2011; Issenberg, McGaghie, Petrusa, Lee Gordon \& Scalese, 2005; Rystedt \& Sjöblom, 2012).

Naturally, the bulk of research on scenario training has revolved around students acting in the capacity of their future professional roles, e.g., as surgeons, nurses, firefighters, or police officers. Whilst this is a given focus, a common practice in scenario training is that students also partake in what we call "secondary roles", such as standardized patients, victims, bystanders or perpetrators (Sjöberg et al. 2015). A current shortcoming in the research literature is that we know little about what students in secondary roles experience during scenario trai- 
ning (Hopwood, Rooney, Boud \& Kelly, 2016; Mandrusiak et al. 2014; Nestel, Mobley, Hunt \& Eppich, 2014). Emblematic of the dearth of research on secondary roles is the fact there is currently no unified vocabulary for these roles. In health care and medicine they are often labelled as standardized patients, simulated patients (SP), or, if the role is someone other than a patient, "confederates" (e.g., Sanko, Shekhter, Gattamorta \& Birnbach, 2016; Utz, Kana, \& Van Den Broek, 2015). In the military and emergency services, the term "markers" is sometimes used (MSB, 2012).

The use of actors in secondary roles improves realism, leading to learning experiences for the students acting as professionals, but also helps keep situations on track (Nestel et al. 2014) and supports focus on the learning objectives (cf. Dieckmann, Lippert, Galvin \& Rall, 2010). Secondary roles in scenarios are commonly performed by trained (sometimes paid) actors, playing an opponent or relevant "other" (such as a simulated patient; Paquette, Bull, Wilson \& Dreyfuss, 2010). Casting of secondary roles is regularly delimited to teachers (McAllister, Searl \& Davies, 2013), faculty members (Mavis, Turner, Lovell \& Wagner, 2006), alumni (Alfes, 2013), retired professionals (Paquette et al. 2010), or actors from local theatres (Endacott et al. 2012; Brown, Doohan \& Shellenberger, 2005). A common practice in vocational training is also that students, whether at the same or another course level, are used as actors in scenarios. Given this fact, it is a shortcoming that only a few studies specifically have addressed the question of learning for actors in secondary roles.

Mandrusiak et al. (2014) is an example of a study that addressed learning for students in secondary roles as they used survey methods to study the use of senior students as standardized patients for junior students. Their main finding was that senior students, through their experience in secondary roles, gained insights into what it is like to be a mentor and the experience of being a patient. Senior students also reported increased ability in giving feedback, and greater confidence in doing so. Mavis et al. (2006) evaluated a scenario training initiative, wherein faculty members and students complemented professional actors in the role of standardized patients. One main finding from this study was that students acting in secondary roles were able to use the encounter as a learning experience: they gained insights into their own abilities in the situation by understanding the strengths and weaknesses of their peers' actions.

In sum, we conclude that while scenario training itself has been extensively studied, few studies have addressed learning for students who perform in secondary roles in these training activities. Furthermore, the few studies that have employed this perspective indicate that there seems to be a presently unexplored learning potential for students in these roles. With this background, the objective of this study is to further explore learning for students who are acting in secondary roles during scenario training in vocational educational settings. Empirically, we draw on a case study of scenario training in police education, and the research questions we aim to answer are what potential for developing professional knowing there 
is for participants who enact secondary roles in scenario training, as well as how scenario training can be arranged to facilitate learning for students who are acting in secondary roles.

\section{Learning in scenario training}

To explore how acting in secondary roles might facilitate learning, we draw on practicebased learning theory as an analytical lens for our study. From this perspective, learning is understood as an emergent phenomenon that takes place as individuals (in interaction with each other and the structural/material settings they encounter), strive to construe meaning and make sense of experience (Billet, 2014). As stated by Mäkitalo (2012 p.61), learning thus entails gap-bridging and "coordination of actions and perspectives" which allows individuals to carry on with their activities.

Applied to scenario training, this perspective states that learning is seen as an emergent phenomenon, one that arises as participants draw on previous knowledge and interact with each other and the specific structural and social resources embedded in a situation in order to construct meaning from what is going on (Hopwood et al. 2016; Nyström, Dahlberg, Edelbring, Hult \& Dahlgren, 2016; Rooney et al. 2015; Dahlgren, Dahlgren \& Dahlberg, 2012; Boud and Hager, 2012; Hager, Lee \& Reich, 2012). Learning in scenario training is specifically impacted by the fact that this type of training needs to strike a balance between being perceived as vocationally relevant by the involved participants and being prefigured to support learning. Regarding the relevancy of vocational scenarios, these need to be applicable to professional practice, as the goal of scenario training is that participants should gain vocational experience (Sjöberg, 2016; Rystedt \& Sjöblom, 2012). To achieve this, role-playing and interaction are key components to enact a scenario in a way that makes the situation feel authentic for the involved participants (Rooney et al. 2015; Rystedt \& Sjöblom, 2012; Dieckmann, Molin Friis, Lippert \& Østergaard, 2012). However, this does not mean that the scenarios have to be realistic in every aspect (Sjöberg, 2016; Sjöberg, 2014; Rooney et al. 2015). In fact, a common observation in the research on scenarios is that too great a focus on increasing realism in the set-up of scenarios can actually cloud learning, for instance by making a scenario too complex or difficult (Hopwood et al. 2016; Sjöberg, 2014; Alinier, 2011; Beaubien \& Baker 2004). In sum, it can be concluded that to facilitate learning optimally, scenarios need to be set-up to provide relevant experiences and the right level of difficulty.

\subsection{Theoretical framework}

Based on the above described perspective on learning, we conclude that interacting social and structural factors are important to include in an analysis of learning in scenario training. In the following, we will be focusing specifically on how learning is facilitated through struc- 
tural and situated domains of scenario training. These dimensions of a scenario are further discussed using the concepts of set-up, prefiguration, doings and sayings, and embodied experience.

The structural aspect of learning in scenario training is analysed by focusing on how situations are designed through the set-up of training activities, and on how student roles are prefigured (c.f. Hopwood et al. 2016). Set-up refers to the material arrangements and pedagogical design of the exercise, and prefiguration (as it is used in this context) refers to guidance, briefings, and instructions as well as previous experiences, and other types of preparation that guide how participants are expected to act. As such, both prefiguration and set-up entail structuring elements that enable and/or constrain what participants are likely to do in a scenario.

The situated aspect of scenario training entails a focus on how learning is reliant on students' enactment on a moment-to-moment basis. This dimension of learning is of course informed by the enabling/constraining arrangements of the structural domain, but learning can also be analysed as emerging in an ongoing manner. In this regard, learning is impacted by what students experience and what activities they partake in as a scenario unfolds in situ. We will analyse the situated domain of scenario training through the notion of doings and sayings and through the concept of embodied experience. The former targets the performances and enactments that students engage in as they train for scenarios, and the latter describes sensory learning such as sensations that students come in contact with through scenario training and role-playing. Both doings and sayings as well as embodiment seem to be important for how students in secondary roles learn. As stated by Hopwood et al. (2016 p. 173), the experience of taking on a secondary role in scenario training can facilitate quite specific affordances for learning just because it offers a different perspective on doings, sayings and embodiment:

- They [students] [...] take on the doings and sayings of other kinds of bodies they will encounter when they are at work. The pedagogical idea here is that the experience of playing a relative or patient (even if only through speaking the patient's voice) leaves an embodied trace, helping students empathise with others in the "real" world - supporting learning objectives relating to producing professionals.

- Taken together, the notion of a structural arrangements (consisting of scenario set-up and prefiguration of roles) and a situated domain of training (i.e., doings, sayings and embodied experience in situ) will be used to inform our analysis of emergent learning for students in secondary roles (see Table 1). 
Table 1: Theoretical concepts for the study

\begin{tabular}{|c|l|l|}
\hline $\begin{array}{c}\text { Phenomenon } \\
\text { under study }\end{array}$ & \multicolumn{2}{|c|}{ Emergent learning in scenario training } \\
\hline Analytical units & $\begin{array}{l}\text { Structural arrangements } \\
\text { - Set-up }\end{array}$ & $\begin{array}{l}\text { Situational arrangements } \\
\text { - Prefiguration }\end{array}$ \\
& - Doings and sayings \\
& - Embodied experience \\
\hline
\end{tabular}

\section{Methods}

To empirically explore learning in secondary roles, we conducted a case study of scenario training within the context of Swedish police education. To capture the dynamics of scenario training we used a combination of participant observation and a questionnaire.

\subsection{Study settings, sampling, and procedure}

Throughout the two-year basic police training programme, students continuously act in scenario training. The training settings can be shorter role-plays embedded in specific courses in which students role-play against each other in the same course groups, but can also range over longer periods of time such as whole days. In these larger training activities, a common practice is that students role-play as secondary actors against peers from other terms. At the time of our study, the police education was designed so that students acted in secondary roles twice for students in terms other than their own. In their first term, they acted in secondary roles for primary participants in term two, and likewise in term three they acted for students in term two.

The scenario training setting we observed in this study was when students who are in their third term act in secondary roles for students in term two. This means that they know the scenario from when they themselves acted in it and that they also have experience from acting in secondary roles in one other scenario against other students than those from their own course group. Participant observations were conducted in three naturalistic sites of scenario training where groups of students acted as primary as well as secondary participants.

Empirical data was collected simultaneously by three observers at the three sites. The sites were designed as stations wherein a pre-designed situation was presented for groups of students (mainly working in groups of six) in the capacity of police professionals (i.e., primary participants). The primary participants were given instructions that resembled information from a dispatch centre and were then left to handle the various situations to their best of their 
ability. Their enactment was supervised by an instructor and afterwards the groups received feedback on their performance. In total, the observations extended to $24\left(8^{\star} 3\right)$ hours of scenario training at the following sites:

1. The Party (8 hours of observation): This scenario was designed as a situation in which the police are dispatched to deal with a potential case of loitering and the associated legal matters regarding public intoxication and the right to remain in the area. Later, the situation develops so that the police have to give first aid to one of the participants. In this scenario, six students simultaneously acted as primary participants (their future professional selves) and four students performed as secondary participants in the roles of drunk and disorderly persons.

2. Youth Brawl (8 hours of observation): This scenario was designed as a situation in which two groups of youths attack and assault each other verbally and physically; the role of the police is to separate the groups, identify the instigators and talk with the involved individuals afterwards. In this scenario, six students acted as primary participants (their future professional selves) and twelve students role-played members of the youth groups.

3. The Protesters (8 hours of observation): This scenario was set up as a road-block protest by environmental activists against a logging company. Police are called to the site by the landowner, who wants protesters removed. In the scenario, six students acted as primary participants (their future professional selves) and six students participated as loud and agitated protesters. In this scenario, one student is given instructions to take on a leadership role among the protesters.

Observations were recorded through open-ended field notes and a structured observation protocol that was filled out by each observer after the observation periods. In detail, the protocol registered data pertaining to different dimensions of the observation. It included descriptive data such as location, time and date, and objective of the training activity. Observations also included structural and social dimensions of the situation. These included being outside, inside, what tools were used for the activity, how the training activity was designed to prompt or facilitate learning, or what room there was for the participating subjects' self-directed interactions at the site, for instance through opinion sharing. Short notes were logged in relation to each dimension.

In addition to observations, a questionnaire with 14 items was distributed to the students acting in secondary roles in the scenarios shortly after their performances. The questionnaire contained questions about what could be learnt from acting in secondary roles (i.e., what acting in the scenarios meant for developing knowledge of how to handle critical incidents in police practice, and what this meant for an understanding of the feelings and reactions of 
people whom the police acted against). the questionnaire also contained how each enactment contributed to reflection (i.e., to what extent the acting had contributed to reflections on how police should act in critical incidents) and how the students perceived the set-up and prefiguration of scenarios (questions about how well the educational setting gave information for the students to produce a realistic scenario, and whether there was space for feedback and reflection for them as actors). The students gave their answers on a five-point Likert scale, ranging from "very low extent" to "very large extent". The questionnaire was distributed as an online questionnaire and was sent through a learning management platform to the students the day after they had acted in the scenarios. The response rate for the questionnaire was 76 $\%(\mathrm{~N}=68)$, of which $61 \%$ were men and $39 \%$ were women. Two students did not answer the question about gender.

\subsection{Data analysis}

The qualitative data mainly grounded our interpretations of the observed situations and the quantitative measures gave insights into students' first-hand experiences of these situations. As such, the questionnaire functioned as a follow-up in aspects where observations fell short (targeting how participants value activities) and as a validation for interpretations of observational data.

In the analysis of observational data, the objective was to make data-to-theory connections regarding how learning in secondary roles unfolded. This meant that the analysis of observational data was conducted in two main phases. First, an inductive "narrative strategy" was applied (Langley, 1999) wherein we merged open-ended field notes and structured observation protocols into detailed, chronologically coherent narratives of training activities. These narratives provided the basis for further analysis, as they contained contextual details and depictions of the courses of events at the observed scenario training sites. For instance, the narrative regarding the protester scenario contained descriptions of how this specific scenario developed as different groups of students trained during the day.

In the second step of analysis, we mobilized our theoretical framework, specifically the theoretical constructs of structural and situational arrangements as "lenses" for theorizing the observed events. Based on the observations, we described the set-up and prefiguration that the various scenarios contained and how the enactment of scenarios took place from the point of view of an observer. To more directly describe experiences (such as for example embodied experience) we analysed instances in which students verbalized this, and we also made use of quantitative data where students valued their experiences of training.

In both steps 1 and 2 of our analysis of observational data, the use of quantitative results aided our validation of the observations. We calculated questionnaire results as frequencies and percentages of Likert scales at the item level. The findings are presented as stacked 
bar graphs describing how students generally valued their experience as secondary participants in terms of learning (see Figure 1), how students perceived the set-up (see Figure 2), and how students communicated during the training activity (see Figure 3). One example of how quantitative measures validated our interpretative work was that the questionnaire data showed that students appreciated reflection on an individual level, which substantiated our interpretations of how verbal and collective (and hence observable) reflection processes were occurring at the various scenario training sites.

\section{$4 \quad$ Findings}

Initially, it can be concluded that students in secondary roles to a high extent perceived their performances in the scenarios in terms of learning experiences. The results show that more than half of the students, $58 \%$, answered that enactment in the scenario contributed to their understanding of how situations in general could be handled by the police to a large or very large extent, and as many as $78 \%$ answered that they had gained an understanding of how police should handle the specific situation they had acted in. Furthermore, $82 \%$ of the students reported that the enactment had contributed to personal reflection on how actions taken by the police shape how events unfold. The strongest results concern the insights into how each situation is to be treated by the police (86\%), and personal reflections on how they themselves would act in similar situations ( $86 \%$; Figure 1).

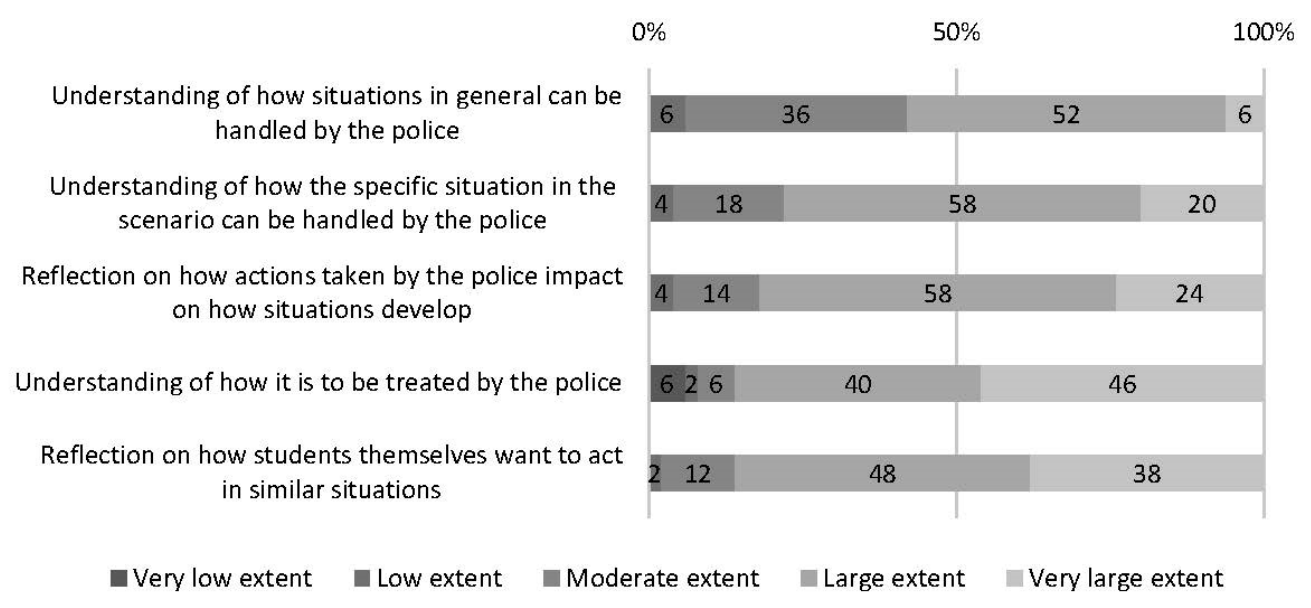

Fig. 1: Extent to which acting in secondary roles contributes to learning experiences 
In the following section, we expand on these findings and describe the learning potential for students who are acting in secondary roles in more depth, based on a blend of observational data and questionnaire data. Specifically, we describe how the structural and situated arrangements of the social situation impacted emergent learning in practice.

\section{$5 \quad$ Structural arrangements}

With regard to structural arrangements, the students who act in secondary roles can be concluded to had an active part as co-creators of the scenarios for the primary participants. As such, they take on a slightly different position to that of a student undergoing training: they become facilitators of learning through their enactment. This instrumental position in the setting alters the power dynamics and relations between the students and instructors, as they become more reliant and co-dependent on each other for the implementation of the planned activity.

In this position, the arrangements that secondary participants experience differ from those experienced by the primary participants. For instance, the set-up directed to the secondary participants contained briefings from the instructors about what the different scenarios were about, both on a surface level and in terms of the learning objectives. However the briefings was not explicit and systematic for all the groups. Briefing information was not always disclosed to the primary participants, as this could run the risk of spoiling surprise elements in scenarios. Furthermore, briefings also outlined how the training activity was going to play out during the day, and usually outlined the instructors' expectations for the secondary participants to provide feedback to the students under training. This type of set-up, whilst not having learning as its primary aim, contains some elements of "backstage information" about how the instructor, with the help of the secondary participants, wanted to design the activity. Examples of briefings were when instructors in the protester scenario gave the students directions to be loud in their protests, but also receptive to how the primary participants communicated so that a good dialogue between police and protesters could alter the outcome of the scenario. Another example of how students in secondary roles were co-creators of scenarios was when an instructor in the protester case informed the students about the objective, and they then jointly designed the scene:

The instructor describes how the landowner has called the police, and how the owner wants the protesters to disperse so he can get through. The instructor also says that they (actors) should be loud. Furthermore, the instructor also points out that communication is important [for the police - observer interpretation] and that they (actors) should listen to the police and decide if they communicate well. If so, they can be a little more helpful. The instructor also mentions that they will give feedback to the "police officers" afterwards, and continues to say that somebody needs to take on the role of a leader of the protesters - "to see if the police officers can differentiate them". But, it is not specified much about how they should act. [...] 
[...]The students try to figure out how they should do the scenario, as they continue to have a discussion among themselves. They tentatively discuss matters such as "which protest chant should we have?" and "who will be leader?" [...] they arrange props and build a barrier of obstacles in front of the place they are going to sit and they seem to get themselves ready for what is to come (observational notes from protester scenario).

Another key part of the training was the feedback session that followed the enactment component. In the session, the group of police students who had acted in the scenario started by describing the situation, how they interpreted it, and their actions. After this, the instructors and students in secondary roles provided feedback to the police group. Peer feedback from students regularly revolved around specific tactical and technical details, such as "it did not feel good to be dragged that way" (in the protesters scenario), or criticizing how the police patrol had handled one of the drunk youths that sat by the campfire holding a knife (in the party). The feedback could also point to and explain how they perceived the police officers: "you were a little awkward" (the party) or "you looked angry" (the protesters).

The notion that secondary participants received a set-up that was more directed at the task at hand rather than at their own leaning is also validated by data from the questionnaire. The answers show that students highly valued the instructions for creating the situations aimed for in the scenarios. The general opinion of the students was that the instruction they received contributed to a large or very large extent $(84 \%)$ to creating the situations aimed for. However, we can also see that $42 \%$ of secondary participants considered that the set-ups contributed to their personal learning experiences to only a low or moderate extent (Figure 2). Likely, this result is a reflection of the task-oriented briefings.

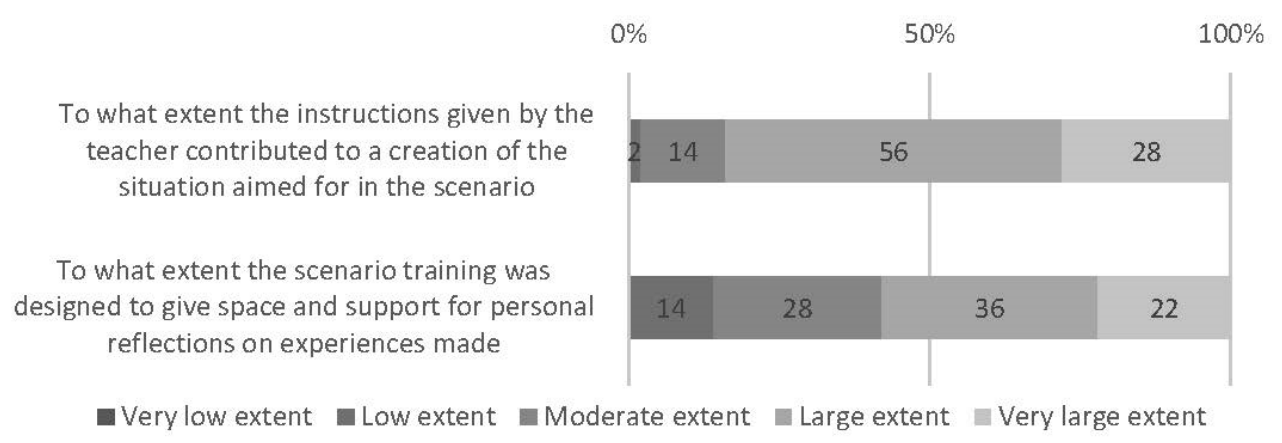

Fig. 2: Set-ups for secondary participants in the scenarios 
With regard to the secondary participants' prefigurations, two aspects stood out in both the observational and the questionnaire data: first, that prefiguration was largely self-directed and drew on students' own experiences from previous scenario training, and second, that repetition in the role of secondary participant offered the possibility to improve scenario performance.

As described earlier (set-up), the first aspects of prefiguration were described in different ways and to different extents in different scenarios. Concerning the second of these aspects, the students who were acting in secondary roles had previous experience of similar types of scenario training and, in addition, experience of the specific training activities, but from the perspective of primary participants. In the breaks between acting, students' talk and interactions displayed attempts to recollect their own experiences as a basis for their enactment. In our interpretation, these types of experiences enabled the students to partake in scenario training with new outlooks compared to their previous experiences when acting as police officers. The quote below exemplifies how previous experiences shaped how students saw their role as secondary participants:

[...] the students discuss their previous experiences of when they partook in the same scenario training in the role of police officers, and they describe various episodes and events that happened then. This includes how uncertain they felt of how to act as police officers, and especially what legal basis they had for different actions. This legal insecurity seems to be a common and widely shared memory of this exercise (Observational notes - assembly and walk to site).

The third aspect of prefiguration that stood out in the data was the significance of repetition and adaptation of enactment over time. In the observations, it became apparent that the outcomes of the scenarios varied for different groups of students.

When the police patrol has left, the two teachers discuss the first two scenarios with the secondary participants. They jointly talk about how differently the situations developed for the first and second patrols (Observational notes - youth brawl scenario).

Often, the actions of the primary participants prompted responses from secondary participants, so that it was the interaction (doings and sayings) between police and other actors that determined the situation and its possibilities in situ (Reich \& Hager, 2014). With repetition, the students became more secure in their actions to create the situation aspired to in the scenario: when repeating a scenario, the space of possible outcomes increased as the secondary participants expanded their experiential knowledge base. 


\subsection{Situated arrangements}

When analysing students' doings and sayings and embodied experiences in relation to the enacted situations, it becomes clear that the situated arrangements affect two important aspects of the scenario training. The first aspect is how participants in secondary roles interact to facilitate good learning opportunities for the primary participants, and the second aspect is the learning emerging for participants in secondary roles when they enact the "other" and in the informal discussions between scenarios.

The observations show how informal discussions amongst the secondary participants influence how scenarios unfold. Students regularly discussed their performances between scenarios, and the quantitative data show that these discussions were important in making sense of their roles. In fact, $84 \%$ of the students reported that these discussions supported their creation of the situations aimed for in the scenarios to a large or very large extent (Figure 3).

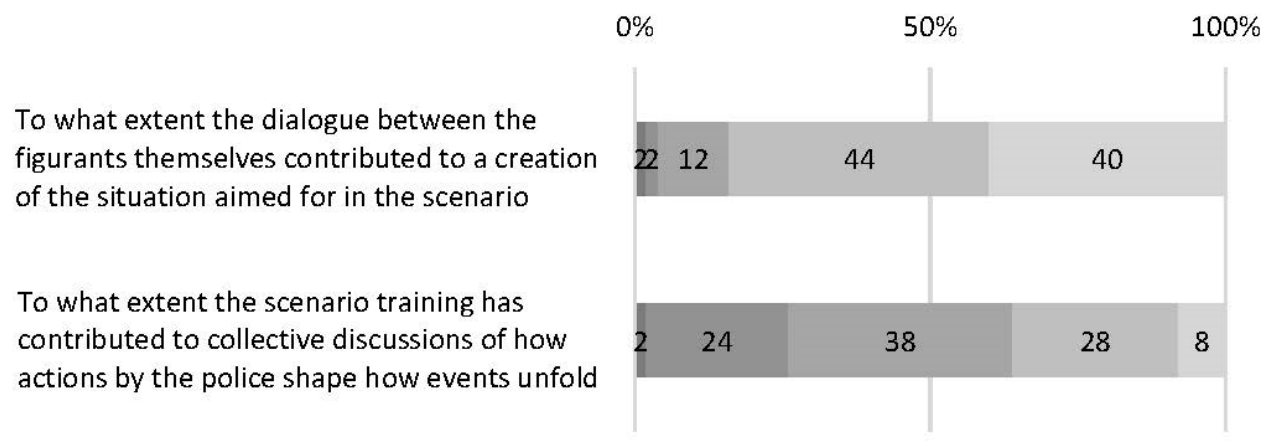

very low extent $\square$ Low extent $\square$ Moderate extent $\square$ Large extent $\square$ Very large extent

Fig. 3: Communication about scenario training amongst secondary participants

This finding means that both instructions (see Figure 2) and informal discussions contribute to students' creation of the situations in the scenarios. While talk was important during scenario training, figure 3 also indicates that transferability of these types of discussions outside the immediate training context occurred to a lower degree. Here, $36 \%$ of the secondary participants reported that enactment contributed to further discussions to a large or very large extent, of which only $8 \%$ answered that this occurred to a very large extent.

In addition to ongoing small talk about how to enact and adjust scenarios during the training activity, we also observed how students in secondary roles regulated the scenario in quite subtle ways, based on their interpretations of how things were unfolding. They could, for example, adjust the scenario's difficulty, "hinting" at matters that the primary participants 
had overlooked, keeping the situation on track despite differences in performance from the primary participants. One example of this was in the party scenario:

The actors soon give clues that there is one person missing (by asking each other questions). The police do not really consider these clues. The actors hint a little more clearly about this and then the police officers begin to search. They then find the person quite quickly (observational notes - the party scenario).

Other examples of adaptation were in altering their behaviours in relation to the actions of the police. For example, in the youth brawl scenario, the secondary participants could escalate their noise level if the police students did not pay attention. Similarly, in the protester scenario, the level by which the secondary participants were willing to cooperate with the police students was directly dependent on how the police behaved towards them. Aspects such as these made the scenarios highly dynamic. In the example above, cue-giving was incorporated into the interaction by the secondary participants based on the difficulties they perceived the primary participants to be experiencing, or on their interpretations of courses of events.

In addition to adaptation based on how secondary participants interpreted the primary participants' enactment, scenarios could also develop differently based on who the secondary participants were, and what difficulties and challenges they experienced in performing the roles that had been handed to them. Overall, the secondary participants reflected on the challenges of shaping the roles in terms of finding the right level of acting. Questions could include how drunk a student should act, or how much they should resist for the scenario to unfold as planned.

In the observations, there were also explicit instances indicating how learning emerged for secondary participants. For example, after the second police patrol had left the youth brawl, students discussed why the latest patrol managed better in the scenario than the previous one.

[...] secondary participants attributed the fact that the first patrol stopped and gained an overview before they acted as a significant success factor (for a good solution to the scenario - observer) (Observational notes - youth brawl scenario).

This example show how secondary participants made some clear insights into police work by discussing the different approaches of two police patrols they encountered. They construed meaning through interaction with each other and the structural/material settings they encountered in the scenarios. Further, when giving feedback, the students were forced to formulate their thoughts and experiences of seeing and interacting based on their alternate outlook as secondary participants. One example of such feedback was found in the party scenario: 
[...] secondary participants at the campfire expressed that in their view, the police did well with their communication. At first when they (secondary participants) tried to approach their injured friend, they had not been allowed access, something that initially caused frustration. However, the police had done well to explain that they could not go to the injured friend because they were trying to help him with first aid. Furthermore, the officers kept track of their arrival time and radioed that information to the ambulance. This information was perceived as calming to the secondary participants [...]. The police officers had also engaged the persons (secondary participants) at the campfire with questions that could help their friend - if he was injured or had any illnesses earlier, and the police had said "come on now, let's do this together" (help the injured person). Secondary participants concluded that this was a good approach, since it made them feel involved (observational notes - the party scenario).

Meeting with the professional practitioners that they aspire to become in the role of the "other" (embodied experience) seems to have made an impression on the students, as this was frequently discussed between the scenarios. One example to illustrate this from the protester scenario:

I hear someone commenting on how the police officers acted and how it made them feel - I then ask the group what they think about the police's actions? The participants in secondary roles respond jointly what they think about the behaviour, body language and tactics of the police officers. One says, for example, that "I think of how they make me feel ..." Another actor says, "I think they should tear down the obstacle (to facilitate moving the protesters) but that they must tell the protesters why they do this" (observation notes - the protester scenario).

The embodiment of the "other" as a resource for learning could also be quite direct and sensory, as was the case in the party scenario, when a student who acted in the role of a person with a skull trauma got to experience how the police students put on a neck brace at a slightly wrong angle, resulting in breathing difficulties. In sum, both enactment against students who were performing as police officers and the verbal feedback that students gave each other are part of the learning process for secondary participants.

Learning through embodied experiences was also confirmed by the questionnaire, wherein $78 \%$ of students answered that their experiences as secondary participants had developed their understanding of how the police ought to deal with the specific situations they had enacted to a large or very large extent (see Figure 1).

We have in this section tried to unpack learning in scenario training for students in secondary roles using some theoretical concepts. To summarize the findings and in order to clarify the connection between the theoretical and analytical concepts and empirical examples, a table is used to visualize this. 
Table 2: Summary of how the theoretical concepts unpacked learning in scenario training for secondary participants.

\begin{tabular}{|c|c|c|c|c|}
\hline Phenomenon & \multicolumn{4}{|c|}{ Emergent learning in scenario training } \\
\hline Analytical units & \multicolumn{2}{|c|}{ Structural arrangements } & \multicolumn{2}{|c|}{ Situational arrangements } \\
\hline \multirow{4}{*}{$\begin{array}{l}\text { Concretized in } \\
\text { the findings }\end{array}$} & Set-up & Prefiguration & $\begin{array}{l}\text { Doings and } \\
\text { Sayings }\end{array}$ & $\begin{array}{l}\text { Embodied } \\
\text { Experience }\end{array}$ \\
\hline & $\begin{array}{l}\text { Support primary } \\
\text { participants in } \\
\text { relation to learning } \\
\text { objectives }\end{array}$ & $\begin{array}{l}\text { Previous experiences } \\
\text { of both scenario } \\
\text { training and this } \\
\text { exercise }\end{array}$ & $\begin{array}{l}\text { Interacting in new } \\
\text { roles }\end{array}$ & $\begin{array}{l}\text { Enact the "other" in } \\
\text { the scenario }\end{array}$ \\
\hline & & $\begin{array}{l}\text { Briefings on the } \\
\text { relation; learning } \\
\text { objectives - scenario } \\
\text { content }\end{array}$ & $\begin{array}{l}\text { Formulating } \\
\text { feedback }\end{array}$ & $\begin{array}{l}\text { New perspectives on } \\
\text { encountering the } \\
\text { police }\end{array}$ \\
\hline & & $\begin{array}{l}\text { Repetition in the role } \\
\text { of secondary } \\
\text { participant }\end{array}$ & $\begin{array}{l}\text { Reflective spaces: } \\
\text { Informal discussions } \\
\text { between scenarios }\end{array}$ & $\begin{array}{l}\text { Difference in how } \\
\text { scenarios play out }\end{array}$ \\
\hline
\end{tabular}

\section{Discussion}

The present study was designed to explore the learning potential for participants who enact secondary roles in scenario training. Secondary roles are something previous research on scenario training and live simulations has largely overlooked (Mandrusiak et al. 2014; Nestel et al. 2014). When narrowing the subject to the learning potential for students who are enacting the "other" in training, the dearth of research becomes even more obvious (Mavis et al. 2006).

To remedy this shortcoming, the present study examined structural and situational aspects of training situations and how students in secondary roles valued their experiences of performing in these roles. A specific aspect of learning in scenario training for those in secondary roles seems to be that the learning primarily is unintentional, because the students' participation in scenario training is motivated mainly by instrumental arguments and not by learning objectives in course plans or syllabi. Our review of previous research showed that the purpose of these roles is to support the primary actors and their learning from the inside (cf. Dieckmann et al. 2010; Smith, Gephardt \& Nestel, 2015). As showcased by our study, however, this does not mean that no learning takes place for secondary participants. Rather, this role offers possibilities for learning that other roles in scenario training do not provide. In the following, we theorize and draw out three specific dimensions for how learning emerges in the training situation for secondary participants in terms of embodying the "other", sensory experience, and reconstruction by repetition. A striking finding of our study was the 
learning potential of embodying the "other" in scenario training. Embodiment meant that students got to perform and enact situations where they interacted with the police from a different standpoint than that of a (developing) professional practitioner. Previous research has shown that opportunities to shift or move in and out of roles, such as a patient, a customer, or a pupil, can be a strong resource for learning in professional and vocational education. Such alterations, through the provision of a partial outsider perspective, can facilitate reflection on learning and practice (Hopwood et al. 2016). In the case reported on here, such reflections were reported on in the questionnaire, but were also noted by observers: in their verbal reflections on participation, students pointed to how the roles made it easier for them to connect their own previous knowledge and experiences of acting in the capacity of a police officer to the experiences of being handled by police.

Closely connected to the embodiment of the "other" is a sensory dimension of learning that was observed on several occasions within the scenarios. An example illustrating this kind of learning, which is grounded in sensory experiences, was the student who got breathing problems because of the incorrect application of a neck brace. Being addressed and approached in more or less successful ways by peer students enacting police officers provided embodied experiences, through which the students seemed to develop professional knowing. This was also indicated by the questionnaire, as $86 \%$ of the students thought that the enactment to a large or very large extent gave them an understanding of how it is to be treated by the police, and also how they themselves want to act in similar situations (see Figure 1). These results show how acting as a secondary participant contributed to a direct firsthand understanding, and, as a consequence, a reflection on how they themselves will act as professionals. This is a form of knowing that cannot be achieved by acting "only" in the role of a professional and while professional experience is useful, it is limited in scope. It is also hard to facilitate from a more distanced or detached position. The role of the other is needed in combination with the professional and in this regard embodying a secondary participant seems to hold a compelling potential for learning.

In addition to the above presented, we also encountered a somewhat unexpected form of learning in the study: namely that, due to their instrumental role, secondary participants in scenario training experienced repetition in their enactments to a higher degree than primary participants. In the observational material, students frequently highlighted their astonishment over how the scenarios unfolded in slightly different ways for the various groups of primary participants who trained during the day. Through repetition and variation in how the scenarios played out, the secondary participants expressed that they gained an understanding of how actions, responses, communication and tactics in a very concrete way shaped what the scenarios became. This was expressed in feedback sessions as something they had not understood when they themselves performed in scenario training as police officers. Thus, by repetitive encounters with various groups, the students reconstructed their professional 
knowing of how the scenarios they acted in could be handled by the police (see also Figure 1). The results accordingly indicate that learning of professional knowing relevant for policing has emerged among the students in secondary roles as a result of their enactment in the scenarios (see Hopwood et al. 2016; Nyström et al. 2016; Rooney et al. 2015).

A final point that can be made based on the findings concerns scenario training and selfreported non-learning. In this regard, between $2 \%$ and $8 \%$ of the students who answered the questionnaire experienced that participation in secondary roles contributed to learning only to a low or very low extent (Figure 1). As the study design doesn't allow us to link observational data to questionnaire results of individual respondents, we are hesitant to draw far-reaching conclusions with regards as to why this variation in student responses is evident. However, a plausible explanation drawn from our observations is that students seem to vary in how comfortable they are in role-playing. Less confident actors may thus manoeuvre themselves to peripheral positions in the situations with fewer interactions. Similarly, the set-ups of various scenarios also naturally differ in how central (or conversely peripheral) a particular secondary role is, so that some roles might contain little interaction between the student actors and the police under training. These circumstances may explain why $8 \%$ of the students reported that their experience of role-playing in secondary roles only to a low or very low extent aided their understanding of how it is to be treated by the police. In all, we conclude that the issue of non-learning in scenario training lends itself well to further examination in future studies.

In summary, the findings suggest that the experience of assuming a secondary role in police scenario training seems to aid police students in their development towards professional practice, as it gives insights that otherwise are hard to make available. In this light, our findings point towards the conclusion that there might be an unrealized potential to adapt scenario training to also take secondary participants' experiences into account for developing professional knowing. We now move on to discuss how such ambitions might be undertaken in practice.

\subsection{Scenario training design and learning in secondary roles}

The research review conducted in this study shows that learning for secondary participants is often overlooked in scenario training. This is also the case in our study, as learning objectives as well as scenario design are adjusted to the primary participants. This means that learning for students in secondary roles is unintentional, informal and variable as it is highly dependent on how students individually choose to navigate and act in the situations they take part.

However, the narrow view of learning in scenario training could with relatively few measures be widened. For instance, the set-up for participants in secondary roles can include activities before and after the scenario training. We suggest that activities beforehand should 
include preparation of the role-playing aspects and prefiguring the learning potential for those in secondary roles. Not least this would aid students who are initially uncomfortable with role-playing to be better prepared and more active in the situations instead of withdrawing themselves to a peripheral position with less interaction. The activities should be aimed at building "simulation competence", or knowledge about the general conditions for learning in scenario training, and about not only what is specific about the current scenario (see Sjöberg 2016; Rystedt \& Sjöblom 2012 for discussion of simulation competence), but also an understanding of the learning potential for actors in different roles. Simulation competence includes knowledge of the ground rules for the scenario, such as shared responsibility, frames of the scenario, and how to handle breaches and uncertainties.

Simulation competence also includes preparing for role-playing, such as deeper knowledge of the kind of situations aimed for and the roles to enact. Prefiguring should rest on clear learning objectives for those in secondary roles and include clear explanation of the learning potential for those enacting these roles. This includes explaining how students, by immersing themselves in the role of the "other" in scenarios and seeing situations from a perspective other than their professional selves, can develop professional knowing (c.f. Hopwood et al. 2016; Mandrusiak et al. 2014). After the scenario training, a seminar design can be used, wherein the students from various scenarios can share their "other" experiences. Here, there is an opportunity to draw out aspects they feel are important for the development of professional knowing (cf. Crookall, 2010). Both before and after the scenario training, as well as between the different scenarios, the instructor can play a key role as a scaffold and support, focusing specifically on the experiences of students enacting secondary roles (cf. Rooney et al. 2015).

The before and after perspectives target how preparation can be mindfully directed for students in secondary roles as they are withdrawn from the scenarios, but we also identify a learning potential which is of a more direct situational nature. This is the learning that was observed to emerge in a self-directed manner momentarily between scenarios, namely situated reflections over the enacted situations. Thus, we believe there is a potential to work with "reflective spaces" (see Baud, 2006) during small, naturally occurring breaks in the scenarios. In such spaces, students have opportunities to share and discuss the professional situation on their own, but also with support from an instructor. We argue that this enables collective reflection and discussions in ways that can inform students by connecting their shared experiences with their "future professional selves". These suggestions can become important ingredients in a scenario training (live simulation) pedagogy that also includes secondary roles, which we see as a take-home message for developing these kinds of activities in vocational education. 


\section{References}

Alfes, C. M. (2013). Nursing alumni as standardized patients: An untapped resource. Clinical Simulation in Nursing, 9(12), e593-e597.

Alinier G. (2011). Developing high-fidelity health care simulation scenarios: A guide for educators and professionals. Simulation and Gaming, 42, 9-26.

Andersson, A. (2016). Boundaries as mechanisms for learning in emergency exercises with students from emergency service organisations. Journal of Vocational Education and Training, 68(2), 245262.

Boud, D. (2006). Creating the space for reflection at work. In D. Boud, P. Cressey, \& P. Docherty (Eds.), Productive Reflection at Work (pp. 158-169). London: Routledge.

Boud, D., \& Hager, P. (2012). Re-thinking continuing professional development through changing metaphors and location in professional practices. Studies in continuing education, 34(1), 17-30.

Bland, A. J., Topping, A., \& Wood, B. (2011). A concept analysis of simulation as a learning strategy in the education of undergraduate nursing students. Nurse Education Today, 31(7), 664-670.

Beaubien, J. M., \& Baker, D. P. (2004). The use of simulation for training teamwork skills in health care: how low can you go?. BMJ Quality and Safety, 13(suppl 1), i51-i56.

Brown, R., Doonan, S., \& Shellenberger, S. (2005). Using children as simulated patients in communication training for residents and medical students: a pilot program. Academic Medicine, 80(12), 1114-1120.

Childs, M. (2005). Beyond training: new firefighters and critical reflection. Disaster Prevention and Management: An International Journal, 14(4), 558-566.

Crookall, D. (2010). Serious games, debriefing, and simulation/gaming as a discipline. Simulation and gaming, 41(6), 898-920.

Dahlgren, M. A., Dahlgren, L. O., \& Dahlberg, J. (2012). Learning professional practice through education. In P. Hager, A. Lee, \& A. Reich (Eds.), Practice, Learning and Change: Practice-theory perspectives on professional learning (pp. 183-197). Springer, Dordrecht.

Dieckmann, P., Lippert, A., Glavin, R., \& Rall, M. (2010). When things do not go as expected: scenario life savers. Simulation in Healthcare, 5(4), 219-225.

Dieckmann, P., Molin Friis, S., Lippert, A., \& Østergaard, D. (2012). Goals, success factors, and barriers for simulation-based learning: A qualitative interview study in health care. Simulation and Gaming, 43, 627-647.

Endacott, R., Scholes, J., Cooper, S., McConnell-Henry, T., Porter, J., Missen, K., ... \& Champion, R. (2012). Identifying patient deterioration: Using simulation and reflective interviewing to examine decision making skills in a rural hospital. International Journal of Nursing Studies, 49(6), 710-717.

Hager, P., Lee, A., \& Reich, A. (2012). Problematising practice, reconceptualising learning, imagining change. In P. Hager, A. Lee, \& A. Reich (Eds.), Practice, learning and change: Practice-theory perspectives on professional learning (pp. 1-14). Dordrecht: Springer.

Hopwood, N., Rooney, D., Boud, D., \& Kelly, M. (2016). Simulation in higher education: A sociomaterial view. Educational Philosophy and Theory, 48(2), 165-178.

Issenberg, S., McGaghie, W. C., Petrusa, E. R., Lee Gordon, D., \& Scalese, R. J. (2005). Features and uses of high-fidelity medical simulations that lead to effective learning: a BEME systematic review. Medical teacher, 27(1), 10-28. 
Kneebone, R. (2005). Evaluating clinical simulations for learning procedural skills: a theory-based approach. Academic medicine, 80(6), 549-553.

Langley, A. (1999). Strategies for theorizing from process data. Academy of Management review, 24(4), 691-710.

Mavis, B., Turner, J., Lovell, K., \& Wagner, D. (2006). Developments: Faculty, students, and actors as standardized patients: expanding opportunities for performance assessment. Teaching and learning in medicine, 18(2), 130-136.

McAllister, M., Searl, K. R., \& Davis, S. (2013). Who is that masked educator? Deconstructing the teaching and learning processes of an innovative humanistic simulation technique. Nurse education today, 33(12), 1453-1458.

Mandrusiak, A. M., Isles, R., Chang, A. T., Choy, N. L. L., Toppenberg, R., McCook, D., ... \& Brauer, S. G. (2014). Senior physiotherapy students as standardised patients for junior students enhances self-efficacy and satisfaction in both junior and senior students. BMC medical education, 14(1), 105.

MSB (2012). Markörer "spelar" en viktig roll i MSB:s utbildningar och övningar. Publicerad: 201209-28 kl. 11:27. https://www.msb.se/sv/Om-MSB/Nyheter-och-press/Nyheter/Nytt-inom-Utbildning/Markorer-spelar-en-viktig-roll-i-MSBs-utbildningar-och-ovningar- $/$

Nestel, D., \& Tierney, T. (2007). Role-play for medical students learning about communication: guidelines for maximising benefits. BMC medical education, 7(1), 3 .

Nestel, D., Mobley, B. L., Hunt, E. A., \& Eppich, W. J. (2014). Confederates in health care simulations: Not as simple as it seems. Clinical Simulation in Nursing, 10(12), 611-616.

Nyström, S., Dahlberg, J., Edelbring, S., Hult, H., \& Dahlgren, M. A. (2016). Debriefing practices in interprofessional simulation with students: a sociomaterial perspective. BMC medical education, 16(1), 148.

Paquette, M., Bull, M., Wilson, S., \& Dreyfus, L. (2010). A complex elder care simulation using improvisational actors. Nurse educator, 35(6), 254-258.

Rooney, D., Hopwood, N., Boud, D., \& Kelly, M. (2015). The role of simulation in pedagogies of higher education for the health professions: Through a practice-based lens. Vocations and Learning, 8(3), 269-285.

Rystedt, H., \& Sjöblom, B. (2012). Realism, authenticity, and learning in healthcare simulations: rules of relevance and irrelevance as interactive achievements. Instructional science, 40(5), 785-798.

Sanko, J. S., Shekhter, I., Gattamorta, K. A., \& Birnbach, D. J. (2016). Development and Psychometric Analysis of a Tool to Evaluate Confederates. Clinical Simulation in Nursing, 12(11), 475-481.

Sjöberg, D. (2014). Why don't they catch the baby? A study of a simulation of a critical incident in police education. Journal of Vocational Education and Training, 66(2), 212-231.

Sjöberg, D. (2016). Simuleringens situerade aktiviteter: Förutsättningar för lärande i polisutbildning [Simulation activities:. Conditions for learning in police education]. (Doctoral thesis, Umeå pedagogik, No. 116). Umeå: Umeå Universitet.

Sjöberg, D., \& Karp, S. (2012). Video-based debriefing enhances reflection, motivation and performance for police students in realistic scenario training. Procedia-Social and Behavioral Sciences, 46, 2816-2824.

Sjöberg, D., Karp, S., \& Söderström, T. (2015). The impact of preparation: conditions for developing professional knowledge through simulations. Journal of Vocational Education and Training, 67(4), 529-542. 
Smith, C. M., Gephardt, E. G., \& Nestel, D. (2015). Applying the theory of Stanislavski to simulation: Stepping into role. Clinical Simulation in Nursing, 11(8), 361-367.

Utz, B., Kana, T., \& Van Den Broek, N. (2015). Practical aspects of setting up obstetric skills laboratories-A literature review and proposed model. Midwifery, 31(4), 400-408.

\section{Biographical notes}

David Sjöberg, $\mathrm{PhD}$, is a lecturer at the Unit for Police Education at Umeå University, Sweden. His research interests include areas such as learning processes in police education and police practice with a specific focus on learning through simulations and scenario training.

Staffan Karp is PhD and Associate professor in Pedagogy at the Department of Education at Umeå University in Sweden. His main research interest is learning processes in police education and police work. Karp has long experience of teaching at the Police Training Programme in Umeå and he has also been Chair of the board of the Unit for Police Education at Umeå University.

Oscar Rantatalo, $\mathrm{PhD}$, holss a position as associate professor at the Department of Education at Umeå University, Sweden. His research interests include areas such as workplace learning, education-work transitions, organizational sensemaking, and policing. 